\title{
Avaliação do efeito da nanopartícula de sílica mesoporosa de Barbatimão, Aroeira e Vitamina E nas linhagens de queratinócito humano (HaCaT) e fibroblasto murino (BALB/c 3T3)
}

Renan K. Jacinto (IC), Prof. Dr. Marcelo Lancellotti (PQ), Dra. Daisy Machado (PQ).

\section{Resumo}

O projeto teve como objetivo desenvolver uma formulação cosmética em forma de emulsão creme, avaliar a estabilidade do produto de acordo com o Guia de Estabilidade da ANVISA e avaliar o efeito da nanopartícula SBA $16 \mathrm{com}$ extrato de Barbatimão, Aroeira e vitamina $\mathrm{E}$ em linhagens presentes na pele, como os queratinócitos humano (HaCaT) e fibroblastos murinho (BALB/c 3T3).

Palavras Chave: Cosmético, Fitoterápico, Nanotecnologia.

\section{Introdução}

O uso de fitoterápico vem crescendo devido ao alto custo dos medicamentos alopáticos, à baixa incidência de efeitos colaterais e à ineficácia de alguns produtos sintéticos. Além disto, o aumento do consumo de produtos cosméticos no Brasil está em plena ascensão. O grupo contém um depósito de patente de uma composição a base de extratos vegetais e nanoesferas de sílica mesoporosa ${ }^{1}$ para carreamento de substâncias ativas pela pele. No presente projeto foi adicionado vitamina $E$ nesta formulação como mais um ativo, apresentando os ativos atividades cicatrizante, anti-inflamatória, antibacteriana, antioxidante, foi realizado à avaliação da citotoxicidade desta composição na pele, através de experimentos in vitro foi realizada por meio de ensaio de viabilidade celular através da redução do MTT e ensaio de viabilidade celular através da incorporação do vermelho neutro.

\section{Resultados e Discussão}

Os testes de estabilidade realizados de acordo com 0 Guia de Estabilidade de Produtos Cosméticos da ANVISA² foram:

Teste de centrifugação: A formulação se manteve estável e sem separação de fases.

Teste de Estabilidade Preliminar: Não apresentando variação dos parâmetros organolépticos, seu aspecto é uma forma semissólida (creme), sua coloração é rosada clara, odor de parafina, e as características físicoquímico são densidade de $0,5 \mathrm{~g} / \mathrm{cm}^{3}$ (gramas por centímetros cúbicos) e $\mathrm{pH}$ de 5,5

Teste de estabilidade acelerada: A formulação apresentou oxidação ficando mais escura que o inicial e apresentou alteração do $\mathrm{pH}$ de 5,5 inicial para 5,0. Testes microbiológicos não observou crescimento de microrganismos.

Teste de prateleira: Com 100 dias de testes a formulação apresentou oxidação da coloração, mantendo as demais características inalteradas.
Teste de compatibilidade entre formulação e material de acondicionamento: Não foi observado nenhuma interação da formulação com o material de acondicionamento.

Ensaio de viabilidade celular através da redução do $\mathrm{MTT}^{3}$ : As linhagens utilizadas foram $\mathrm{HaCaT}$ e BALB/c 3T3 a viabilidade celular foi alta acima de $80 \%$ em comparação com o controle.

Ensaio de viabilidade celular através da incorporação do vermelho neutro ${ }^{4}$ : Foi realizado a exposição às diferentes concentrações da formulação, a viabilidade celular foi alta acima de 85\% em comparação com o controle.

\section{Conclusões}

Neste projeto, podemos avaliar a estabilidade da formulação de acordo com as normas da ANVISA e obtivemos resultados satisfatórios. Devido a formulação não apresentar conservantes, o tempo de validade da formulação não foi tão elevado, no entanto utilizando concentrações maiores de vitamina $E$, que apresenta propriedades antioxidantes, a validade da formulação pode ser estendida. A formulação não apresentou toxicidade significativa nos ensaios de viabilidade celular realizados, se mostrando segura para utilização.

\section{Agradecimentos}

Agradeço ao professor Dr. Marcelo Lancellotti, a Dra. Daisy Machado, aos amigos do laboratório de Biotecnologia Labiotec, por toda ajuda e conhecimentos transmitidos. Apoio Financeiro: Pibic/CNPq.

PATENTE PI018120015848 - Composição a base de extratos vegetais e nanopartículas de sílica de alta absorção: sua formulação e uso.

BRASIL, AGÊNCIA NACIONAL DE VIGILÂNCIA SANITÁRIA. Guia de estabilidade de produtos cosméticos. Brasília: ANVISA, v. 1: Maio, 2004.

${ }^{3}$ Mosmann T. J Immunol Meth 1983; 65: 55-63.

${ }^{4}$ Borenfreund E, Puerner JA. Toxicol Lett 1985; 24: 119-124. 